\title{
An evaluation of management strategies for Atlantic tuna stocks* ${ }^{\dagger}$
}

\author{
L.T. KELL ${ }^{1,6}$, D.J. DIE ${ }^{1}$, V.R. RESTREPO², J.-M. FROMENTIN³, V. ORTIZ DE ZARATE ${ }^{4}$ \\ and P. PALLARES ${ }^{5}$ \\ ${ }^{1}$ RSMAS/CIMAS, University of Miami, 4600 Rickenbacker C., Miami, Florida 33149, USA. \\ ${ }^{2}$ ICCAT, C. Corazon de Maria, 8, 28002 Madrid, Spain. \\ ${ }^{3}$ IFREMER, BP 171, 34203 Sete, Cedex, France. \\ ${ }^{4}$ IEO, Apdo. 240, Santander, 39080, Spain. \\ 5 IEO, C. Corazón de María 8, 28002 Madrid, Spain. \\ ${ }^{6}$ Current address: CEFAS, Pakefield Road, Lowestoft, Suffolk NR33 0HT, UK. E-mail: L.T.Kell@ cefas.co.uk
}

\begin{abstract}
SUMMARY: International agreements for the International Commission for the Conservation of Atlantic Tunas (ICCAT) convention area imply that Atlantic tuna stocks should be managed by strategies based on maximum sustainable yield (MSY); however, there is concern whether this will actually ensure sustainability with sufficiently high probability consistent with the principals of the precautionary approach. Therefore, the performance of MSY management strategies based on current assessment procedures was evaluated using a computer simulation framework. The framework includes the data collection, assessment, prediction, and management processes, as well as the implementation of management regulations. It therefore provides an integrated way to evaluate the relative importance of and the interactions between each component of the system with regard to the overall success of the management strategy. The study elucidates guidelines about assessment and management that are general enough to be applied to all tunas in the Atlantic Ocean. It does so by comparing different hypotheses about management and assessment for three stocks (North Atlantic albacore, Atlantic bigeye and East Atlantic skipjack), which are representative of the variety encountered (i.e. from data rich to poor and tropical to temperate waters) in ICCAT stocks. Management performance was especially sensitive to the carrying capacity of the stock. The type of proxy used for MSY was more important to the success of the procedure than the frequency of assessment or the number of indices used in the assessment. Whilst the procedure was successful at achieving the management objectives for albacore, it was only partially successful for bigeye and was too conservative for skipjack.
\end{abstract}

Key words: albacore, bigeye, skipjack, management, strategy, evaluation, simulation, ICCAT.

\section{INTRODUCTION}

This study uses a simulation framework to develop management strategies, consistent with the International Commission for the Conservation of Atlantic Tunas (ICCAT) Convention. The robustness of these strategies is tested for different manage-

\footnotetext{
*Received December 6, 2000. Accepted May 16, 2002. †British Crown.
}

ment/assessment options and hypotheses about the dynamics of three contrasting tuna stocks. The study stocks were North Atlantic albacore, Atlantic bigeye and East Atlantic skipjack, chosen since they represent a variety of stocks from data rich to poor and from those inhabiting tropical to temperate waters.

Management strategies for Atlantic tunas should be consistent with the precautionary approach (FAO 1996), as embodied in the Code of Conduct for Responsible Fisheries (FAO, 1995) and the Agree- 
ment for the Implementation of the Provisions of the United Nations Convention of the Law of the Sea of 10 December 1982 relating to the Conservation and Management of Straddling Fish Stocks and Highly Migratory Fish Stocks (Doulman, 1995). In addition, management strategies that can be considered by ICCAT are restricted by Article VIII of the Basic Texts which states that "The Commission may, on the basis of scientific evidence, make recommendations designed to maintain the populations of tuna and tuna-like fishes that may be taken in the Convention area at levels which will permit the maximum sustainable catch." Here maximum sustainable catch is interpreted as the Maximum Sustainable Yield (MSY).

However, it has been pointed out (Rosenberg and Restrepo, 1995) that stocks managed to provide MSY may not lead to sustainable and/or optimal management because of:

i) Uncertainties associated with the data

ii) Simplifying assumptions made in modelling biological processes

The Standing Committee on Research and Statistics of ICCAT (ICCAT, 1999a) therefore recommended that current assessment and management systems be evaluated through computer simulations using the type of framework developed by Kell et al. (1999a, b). This allows the reliability of decisions under a variety of plausible hypotheses about the system to be measured directly by comparing the actual realisation of objectives with anticipated results.

Management strategies can be expressed as harvest control rules (HCR), which are pre-agreed actions taken conditionally on quantitative comparisons between indicators of the status of the stock and some sustainability or optimality indicators. These HCR are a form of adaptive management (Walters, 1986). For Atlantic Tuna stocks, a HCR consistent with the Basic Texts is to reduce fishing mortality whenever the biomass of a stock falls substantially below the biomass that would on average produce MSY $\left(\mathrm{B}_{\mathrm{MSY}}\right)$ and/or when fishing mortality substantially exceeds the fishing mortality that on average would produce MSY $\left(\mathrm{F}_{\mathrm{MSY}}\right)$ for a stock. Such a control rule would also have to specify how effort or catch is to be reduced, by imposing quotas or by reducing fishing effort.

Once a proposed management strategy has been coded as an HCR, simulation can be used to conduct experiments that evaluate the response of the fishery system to the strategy. The framework includes mathematical representations of both the 'true' and the observed systems (data collected, assessment model used and reference points used to guide HCRs and their implementation) and so is able to investigate the robustness of management strategies to both the intrinsic properties of the natural system and to our ability to understand, monitor and control them.

Examples of factors that can be investigated are long-term fluctuations in productivity (Fromentin et al., 1999), errors in estimating fishing effort, choices of assessment models, biological reference points and data collection strategies. Importantly, such a framework has the advantage of considering the interactions between all these components and provides an integrated way to evaluate the relative importance of system components for the overall success of management (Wilimovsky, 1985; De la Mare 1998; Holt 1998).

\section{METHODS}

The simulation model framework is illustrated in Figure 1. The "true" stock and fishery dynamics are represented as the operating model, from which pseudo-data are sampled. These data are then used within an assessment procedure to determine the status of the stock and, depending on the perception gained, management controls are applied to the fishery.

The approach is able to model the uncertainties discussed by Rosenberg and Restrepo (1995). These include: process error due to natural variation in dynamic processes (e.g. recruitment, somatic growth, natural mortality); measurement error generated in collecting observations from a population; estimation error that arises from trying to model the dynamic process (i.e. during the assessment process); and implementation error since management actions are never implemented perfectly. These uncertainties can be modelled as random variables for which values are obtained using Monte Carlo simulation. Performance statistics in the form of probability distributions are then collected and used to evaluate the performance of management strategies. Such statistics are related to the management objectives and typically include biological constraints (the probability of the stock being above some minimum biological threshold) and economic measures (value of the fishery catch over time).

The model was written in Visual Basic, calling routines from the FishLab library. This allows for modular programming and helps to ensure the integrity of component algorithms. 


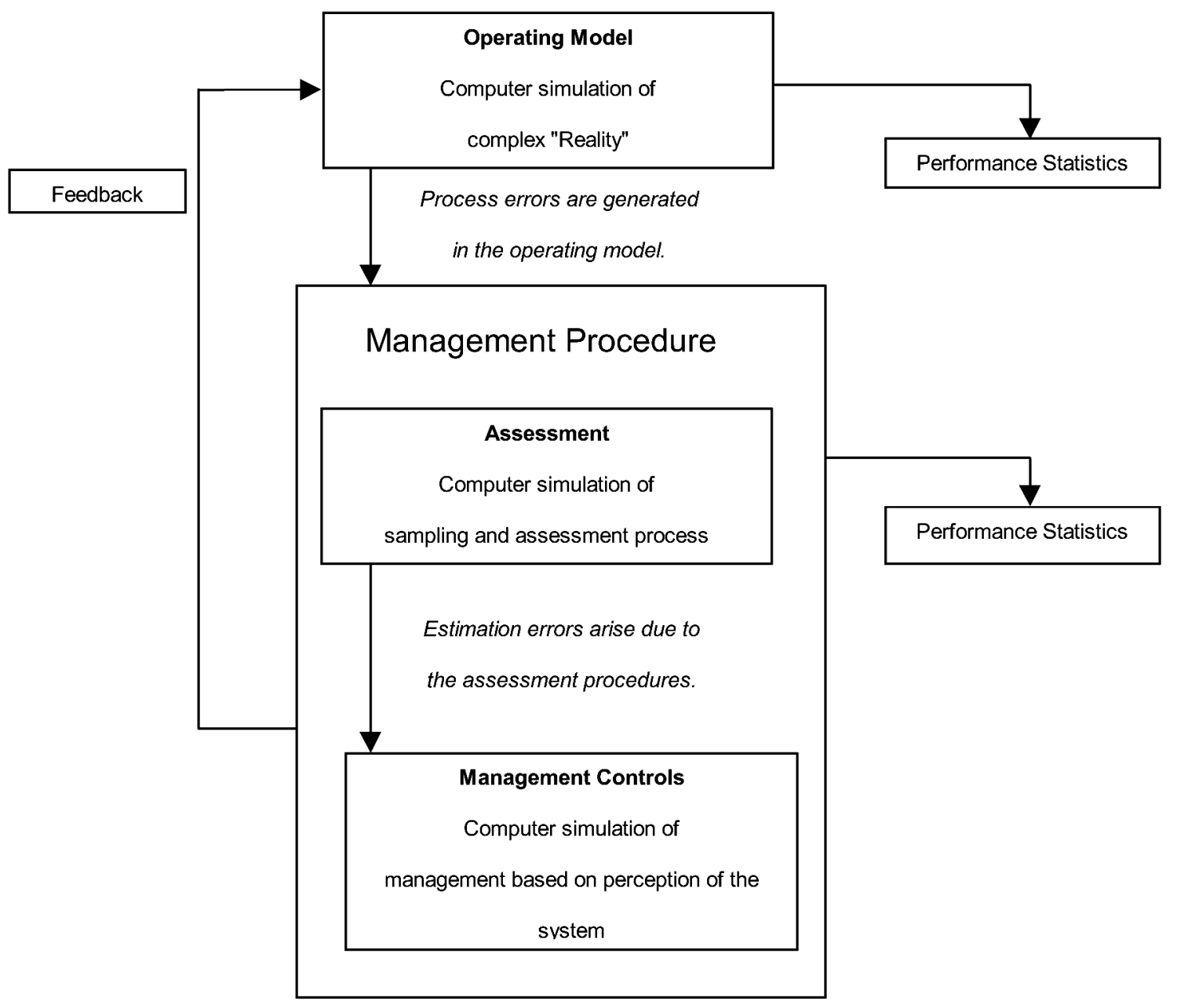

FIG. 1. - Simulation model structure (after ICES, 1994).

\section{The operating model}

The operating model (i.e. the true system) is an age-structured forward projection population model in which recruitment, exploitation pattern, growth, maturity, and natural mortality are modelled as random variables. A greater variety of historic stock status can be modeled using such forward projection models than using virtual population analysis (VPA), the usual assessment method for the study stocks. VPA reconstructs a stock's historic status using total catch-at-age data and the main source of variation is only in the stock status in the current year.

Future stock status is determined by catches, which are set by the management procedure that combines the perception of the stock and the implementation of management. The historical stock is conditioned on both the observed catch and catch per unit effort (CPUE) so that current status is consistent with the observations from the fishery.
Assumptions on selectivity, growth, maturity and natural mortality are consistent with those made by the SCRS ICCAT stock assessment group (ICCAT, 1999b, 2000a, b).

Abundance and fishing mortality at age are obtained using a forward population model constrained for different ratios of current to virgin biomass. The model is then fitted to explain the trends in indices of abundance, given the observed yields and biological characteristics of the stock. The stock recruitment relationship was parameterised in terms of steepness and virgin biomass steepness (Francis, 1992), where steepness was assumed to be less for temperate than for tropical tunas: i.e. 0.6 for albacore and 0.9 for bigeye and skipjack.

Aged structured population model

$$
N_{\text {age,year }+1}=R_{\text {year }+1}
$$




$$
\begin{aligned}
& N_{\text {age }+1, \text { year }+1}=N_{\text {age,year }} e^{-\left(M_{\text {age,year }}+\sum_{\text {fleet }} S_{\text {fleet,age,year }} F M \text { ult fleet,year }\right)} \\
& N_{\text {PlusGroup,year }+1}= \\
& =N_{\text {PlusGroup, year }} e^{-\left(M_{\text {PlusGroup,year }}+\sum_{\text {fleet }} S_{\text {fleet,PlusGroup,year FMult fleet,year }}\right)}+ \\
& +N_{\text {PlusGroup-1,year }} e^{-\left(M_{\text {PlusGroup-1,year }}+\sum_{\text {fleet }} S_{\text {fleet,PlusGroup-1,year } F \text { Mult fleet,year }}\right)}
\end{aligned}
$$

\section{Recruitment}

Recruitment is modelled as a Beverton and Holt stock recruitment relationship

$$
R_{t}=\frac{a S S B_{t-\text { RecruitAge }}}{b+S S B_{t-\text { RecruitAge }}} e^{\varepsilon} e^{-\frac{\sigma^{2}}{2}}
$$

where

$$
\varepsilon \sim N\left(0, \sigma^{2}\right)
$$

A CV for recruitment of $40 \%$ was assumed for all stocks.

\section{Selectivity}

Selectivity is decomposed into age and year effects, which are both modelled as log normal random variables. i.e.

$$
\begin{gathered}
\log \left(\text { Selectivity }_{\text {age, }, \text { Year }}\right) \sim\left(\text { Selectivity }_{\text {age }}, \sigma_{\text {age }}^{2}\right)- \\
-\frac{\sigma_{\text {age }}^{2}}{2}+N\left(0, \sigma_{\text {age }}^{2}\right)-\frac{\sigma_{\text {age }}^{2}}{2}
\end{gathered}
$$

\section{Fishing mortality}

Fishing mortality is modelled as the sum of the partial Fs of the fishing fleets.

$$
\begin{aligned}
F_{\text {age,year,stock }}= & \sum_{\text {fleet }}^{\text {NFleets }} \sum_{\text {area }}^{\text {NAreas }} \times \text { Selectivity } \\
& \times q_{\text {fleet, }, \text { year }, \text { year, fleet.area,stock }} \times \text { Effort }_{\text {year, fleet, area }} \times
\end{aligned}
$$

\section{Catch-at-age}

Catch-at-age is modelled by the catch equation

$$
\begin{gathered}
\text { Catch }_{\text {fleet.age, year }}=N_{\text {age,year }} \frac{F_{\text {fleet, age, year }}}{F_{\text {age, year }}+M_{\text {age,year }}} \times \\
\times\left(1-\exp \left(-F_{\text {age, year }}-M_{\text {age,year }}\right)\right)
\end{gathered}
$$

\section{Natural mortality}

The expected values of natural mortality are given by an age specific vector and are equal to the values assumed in the current assessment. Uncertainty is then modelled assuming that $\mathrm{M}$ at age is multivariate-normal distributed. On ecological grounds, it is expected that similar life history stages will experience similar levels and variations in natural mortality. Therefore, where adjacent age classes had the same expected value a correlation of 1.0 between M-at-age was assumed.

\section{Growth}

Growth was assumed to follow a Von Bertalanffy growth model

$$
\text { Length }_{\text {age }}=L_{\infty}\left\{1.0-e^{-K\left(\text { age }-t_{0}\right)}\right\}
$$

and weight at age was determined by the length weight relationship

$$
\text { Weigth }_{\text {age }}=\alpha \text { Length }_{\text {age }} \beta
$$

Uncertainty in the expected length at age was modelled by making $K$ a random variable within a year i.e.

$$
K \sim N\left(0, \sigma_{K}^{2}\right)
$$

\section{Maturity}

The proportion of individuals mature is considered as an age specific vector; no uncertainty was modelled.

\section{Estimation of effort by fleet}

Effort was estimated for each fleet by solving the catch equation for each fleet. Catch per unit effort was then derived as the ratio of catch to effort.

\section{Calculation of Maximum Sustainable Yield}

If the functional form of the stock recruitment relationship is known, then equilibrium spawning stock can be derived as the product of spawner per recruit (SPR) and recruitment i.e.

$$
\operatorname{SSB}(F)=\operatorname{SPR}(F) \times R(F)
$$


For the Beverton and Holt stock recruitment model, rearranging SSB and R gives SSB as a function of spawner per recruit:

$$
S S B=a \frac{S S B}{R}-b
$$

This allows both spawner per recruit and recruitment to be derived as functions of fishing mortality:

$$
\operatorname{SSB}(F)=\operatorname{SPR}(F) \times R(\operatorname{SPR}(F))
$$

Likewise, equilibrium yield can also be derived as a function of fishing mortality:

$$
\operatorname{Yield}(F)=Y P R(F) \times R(S P R(F))
$$

The maximum value of yield calculated from this relationship corresponds to the maximum sustainable yield (MSY) and the fishing mortality and spawning stock biomass to $\mathrm{F}_{\mathrm{MSY}}$ and $\mathrm{B}_{\mathrm{MSY}}$ respectively.

\section{Conditioning the operating model}

Because of uncertainties associated with the data and model assumptions, current stock status was made a factor in the experimental design. This was possible since the operating model is based upon a forward projection that allows a variety of historic and future responses to exploitation to be modelled. Spawning stock biomass in the operating model at the start of the management period corresponded to one of three states within an experiment:

i) Overfished

ii) Close to $B_{\text {MSY }}$

iii) Underfished

This was achieved by constraining the spawning stock biomass at the start of the management period to be a ratio of the virgin spawning stock biomass (depletion level). The effect of this was to model stocks with different carrying capacities and correspondingly different initial depletion levels (i.e. at the start of the management period). This constraint results in vastly different historical trends for the different biological reference points and stock indicators (Fig. 2).

The forward projection was validated by comparison to the most recent assessment made by ICCAT. In all cases when current stock status in the operating model was similar to that in the assessment, historic time series were also similar.

\section{The ICCAT management procedure}

Although no formal management procedure exists within ICCAT, the assessment approach used for all stocks tends to be very similar (Fig. 3). Assessment process tasks are performed by individual countries, by the secretariat or by assessment working groups. Data on landings (L) are collected by member states; catches are sampled so that the total length frequency distributions of the catches of the various fleets (LF) can be estimated. In addition, indices of abundance (U) are prepared wherever possible by national scientists using effort data. Total catches and the length frequency samples and fishing effort are sent to the ICCAT secretariat for collation and preparation of catch-at-age data.

Total landings and length frequency distributions are then combined by the ICCAT secretariat with a growth model to generate landings by age class (C). The catch-at-age data are then typically analysed using virtual population analysis to derive estimates of numbers $(\mathrm{N})$ and fishing mortality $(\mathrm{F})$ at age. Natural mortality $(\mathrm{M})$ is generally unknown and has to be assumed. Once the current stock status is estimated, projections are made to determine future status of the stock under various catch or effort regimes.

For the purposes of the current study, the above process has been simplified. The operating model generates catch-at-age and effort data that are used to provide estimates of current stock status and productivity. It was assumed that all catches were reported and that there was no discarding. The assessment method used is FADAPT Version 4 (Restrepo, pers. comm.), and the target reference points chosen for use in management were all proxies for $\mathrm{F}_{\mathrm{MSY}}$ i.e. $\mathrm{F}_{0.1}, \mathrm{~F}_{30 \% \mathrm{SPR}}$ and $\mathrm{F}_{40 \% \mathrm{SPR}}$, where $\mathrm{F}_{30 \% \text { SPR }}$ and $\mathrm{F}_{40 \% \mathrm{SPR}}$ are the fishing mortalities that correspond to values of spawner per recruit that are 30 and $40 \%$ respectively of the virgin values (i.e. fishing mortality is zero).

Proxies for MSY and $\mathrm{B}_{\mathrm{MSY}}$ were calculated from the yield and spawner per recruit curves times mean recruitment. A stock projection (where future recruitment is equal to the geometric mean recruitment of the last five years) is then made to estimate catches.

The implied management objective of ICCAT is to maintain the stock at a level that will support the maximum sustainable yield; if the stock is below this level (i.e. overfished), then it has to be rebuilt to or above this level within an appropriate time. If fishing mortal- 
A
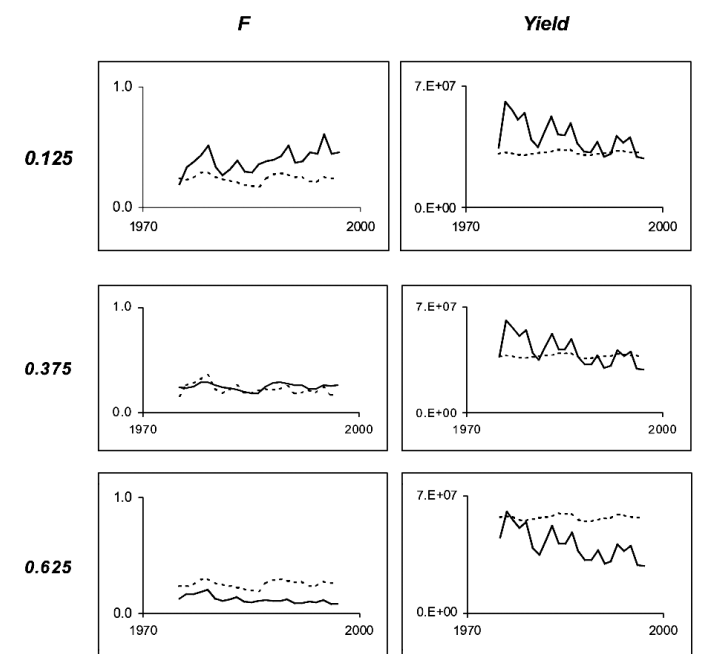

B
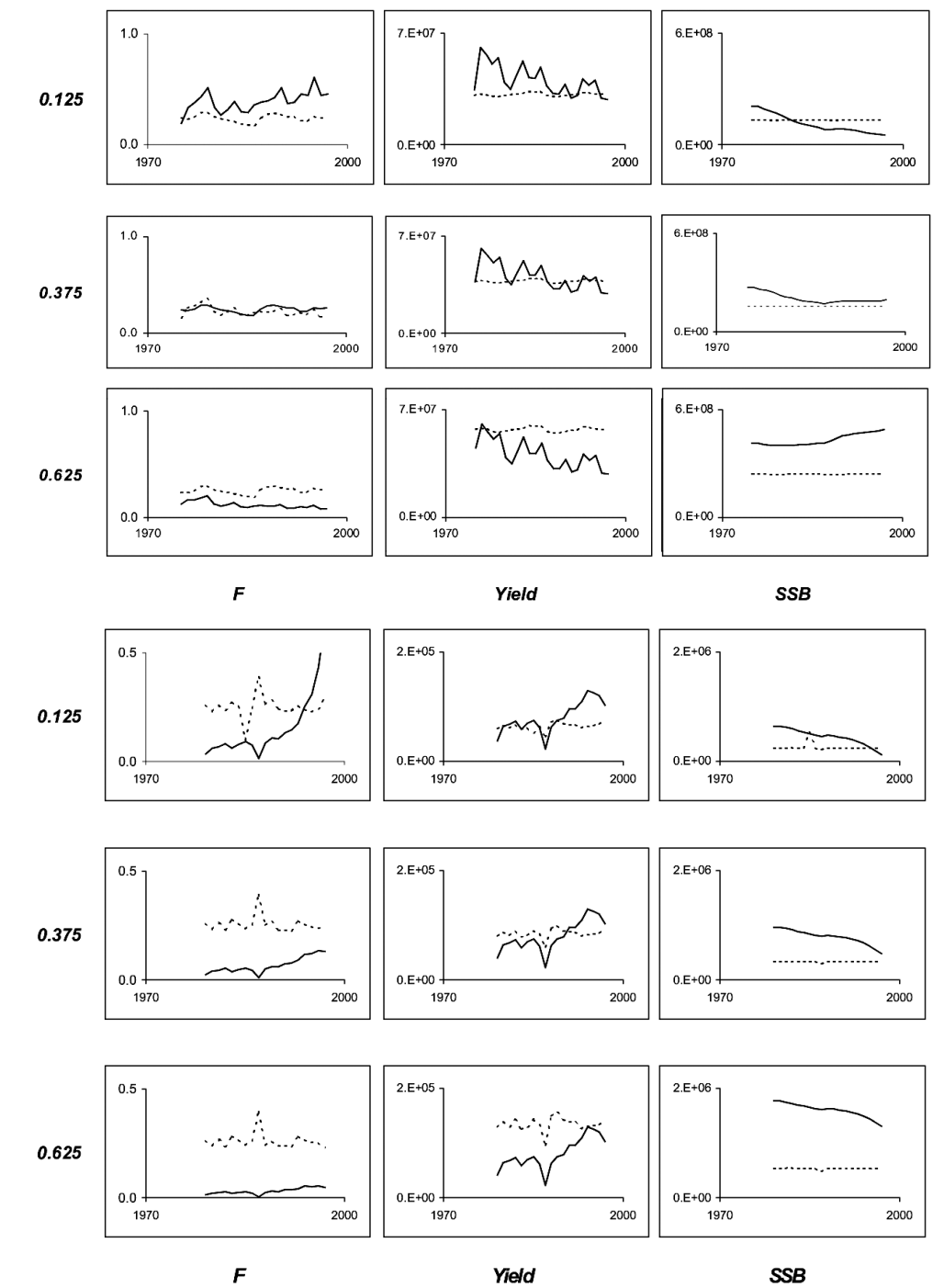

Yield

C
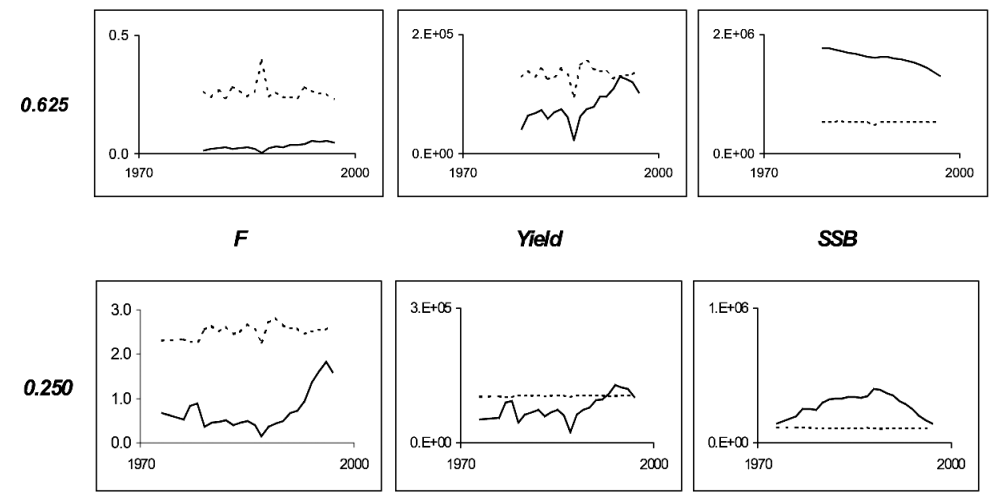

SSB
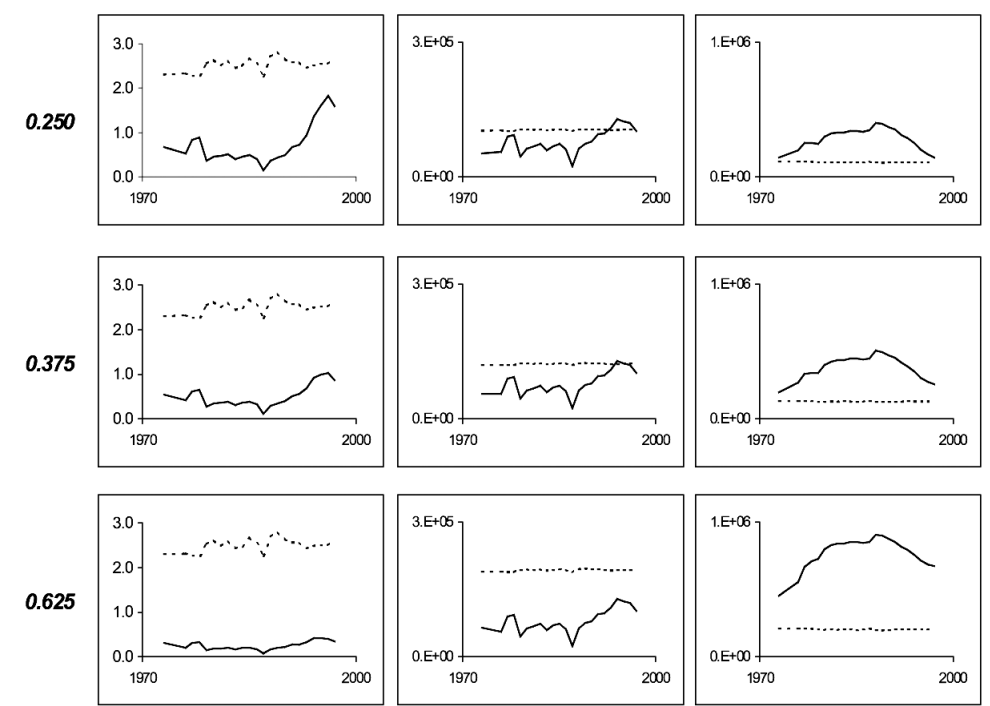

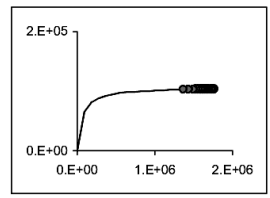

Stock Recruit Relationship
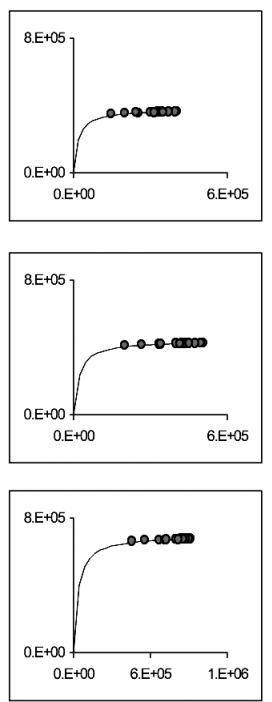

FIG. 2. - Historical stock status (solid lines): Fishing mortality (F), yield and spawning stock biomass (SSB) and spawning stock-recruitment relationships at three carrying capacity levels for a) albacore, b) bigeye and c) skipjack. Dotted lines represent reference points, $\mathrm{F}_{\mathrm{msy}}, \mathrm{MSY}$ and $\mathrm{SSB}_{\mathrm{msy}}$. Circles are the expected recruitments for the expected historical biomasses. 


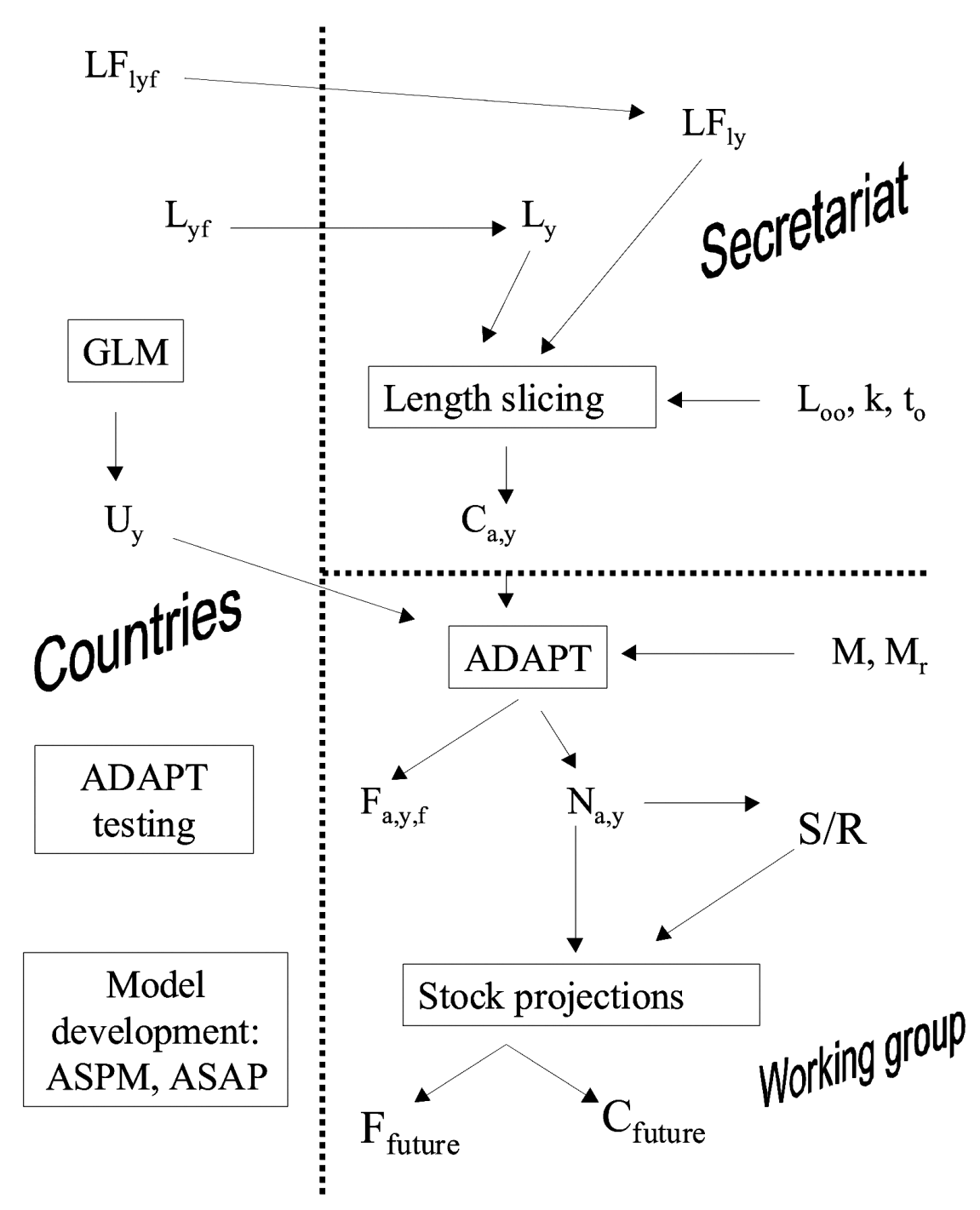

FIG. 3. - Idealised ICCAT assessment process. $\mathrm{L}=$ landings, $\mathrm{LF}=$ length frequency samples, $\mathrm{U}=$ index of abundance, $\mathrm{C}=$ landings by age class, $\mathrm{M}=$ Natural mortality, $\mathrm{L}_{\infty}, \mathrm{k}$ and $\mathrm{t}_{\mathrm{o}}=$ growth parameters, $\mathrm{S}=$ selectivity, $\mathrm{N}=$ Abundance, $\mathrm{F}=\mathrm{Fishing}$ mortality, $\mathrm{S} / \mathrm{R}=\mathrm{S}$ tock- ecruitment relationship, $\mathrm{C}_{\text {future }}=$ Constant catch strategy, $\mathrm{F}_{\text {future }}=$ Constant mortality strategy. Subscripts are: $1=$ length, $\mathrm{a}=\mathrm{age}, \mathrm{y}=$ year, $\mathrm{f}=$ fleet . Dotted lines separates work done by ICCAT countries from that done by the ICCAT secretariat and the ICCAT working groups.

ity is greater than $\mathrm{F}_{\mathrm{msy}}$ (i.e. overfishing is occurring), then $\mathrm{F}$ must be reduced. This objective can be represented in the form of a harvest control rule, although these have yet to be strictly defined by ICCAT for a given stock. Lately, however, some regulations have been imposed to rebuild stocks of species like bluefin and swordfish. In this study we therefore consider a harvest control rule that attempts to rebuild the stock when it is estimated to be overfished:

1. If the spawning stock biomass is below $90 \%$ of that at MSY $\left(\mathrm{B}_{\mathrm{msy}}\right)$, then a rebuilding plan is implemented, i.e. the total allowable catch (TAC) is set to the maximum catch that allows the stock to recover to $B_{\text {msy }}$ within a period of one lifespan.

2. Every time an assessment is conducted, stock status is re-assessed and the TAC is adjusted so that the stock is still projected to reach $\mathrm{B}_{\mathrm{msy}}$ (as estimated at the start of the period) by the original rebuilding date. If the stock does not actually rebuild by the target date, another rebuilding plan is implemented. If the stock is between $\mathrm{B}_{\text {msy }}$ and 1.1 times $\mathrm{B}_{\text {msy }}$ the TAC is not adjusted.

3. If the stock is above $1.1 \mathrm{~B}_{\mathrm{msy}}$, then a development plan is implemented, i.e. the total allowable catch (TAC) is set to the maximum catch that allows the stock to be reduced to $B_{\text {msy }}$ within a period of one lifespan.

4. To prevent meaningless adjustments to the TACs, a rebuilding plan will only be implemented and subsequent TACs changed if catches need to be changed by more than $20 \%$ of the current or the original TAC levels respectively. 


\section{Study Stocks}

Three stocks were chosen to represent the range of Atlantic tuna fisheries, i.e. North Atlantic albacore, Atlantic bigeye and East Atlantic skipjack.

\section{Northern albacore}

Albacore is a temperate/sub-tropical species widely distributed throughout the Atlantic Ocean and Mediterranean. Assessments are currently performed for two stocks (one in the South and one in the North Atlantic). The Northern stock has traditionally been exploited by a long line fishery for sub-adult (age $~ 4$ ) and adult fish (age $\geq 5$ ) and by a surface fishery targeting juvenile (age $<4$ ) and subadult fish. The surface fishery historically comprised bait boats and trollers, but recently pelagic pair trawls and drift-nets have been introduced. The latter are, however, due to be phased out in January 2002.

Individuals mature at age five when they are about $90 \mathrm{~cm}$ in size. Maturity is assumed to be $50 \%$ at age five and $100 \%$ at older ages. Spawning is thought to occur at the beginning of the year (springsummer months).

Routine assessments for the northern stock are performed using primarily ADAPT (Powers and Restrepo, 1992) but alternative approaches like ASAP (Legault and Restrepo, 1998) have been investigated. Both ADAPT and ASAP estimate that the current level of fishing mortality is above $\mathrm{F}_{\text {msy }}$, 25 to $40 \%$ respectively (ICCAT, 1999b).

Management regulations currently in place for the northern stock limit the number of vessels to the average level of the period 93-95 and driftnet length to $2.5 \mathrm{~km}$. Because of the results of the last assessment it is becoming increasingly likely that regulations will be implemented to reduce catches as well.

\section{Bigeye}

The distribution of bigeye tuna in the Atlantic Ocean extends between $50^{\circ} \mathrm{N}$ and $45^{\circ} \mathrm{S}$. The stock is exploited by many different countries using three major gears: long-line, bait boat and purse seine. Growth is relatively fast, with fish reaching $100 \mathrm{~cm}$ by age three. At age three, $50 \%$ of fish are assumed mature and all are mature once they have reached age four.

Bigeye assessments are done assuming there is a single stock. Routine assessments are done with
ADAPT, but other methods include forward Virtual Population Analysis and various forms of production models. No stock predictions have been made because of the contradictory results obtained from the different assessment models. The major regulations are a seasonal spatial closure on juvenile fishing grounds, a minimum size at $3.2 \mathrm{~kg}$ and a limit in the number of vessels to the average level of 19911992.

\section{Skipjack}

Skipjack, found in the tropical and subtropical areas of the Atlantic Ocean, are often associated with floating objects. This behaviour has been exploited by the two main fishing fleets, bait boat and purse seine fleets, since 1991, and it has led to increased catches during the last decade. Growth is highly variable throughout its range and this has precluded scientists from using size- or age-structured assessment models. The species spawns throughout the year.

Skipjack tuna assessments are done with generalised production model assuming two stocks exist, one in the east and another in the west. The seasonal spatial closure on bigeye juvenile fishing grounds also significantly affects skipjack.

\section{Experimental design}

Simulations are run as experiments, allowing the interaction between the management strategies and assumptions about the stock dynamics to be investigated.

Normally it is difficult to compare management procedures across species because data availability, fleet structure and assessment procedures are different between species. In order to be able to compare between species we have simplified the fishery systems and aggregated gears across national fleets and combined minor fleets. The fleets modelled are: longline, purse seine, baitboats, troll and "others", where others may include a combination of gears. The selection pattern of each of these fleets, however, is defined by the data existing for each stock.

In this study we are interested in comparing the performance of particular management strategies under different stock/fishery scenarios, where a management strategy is defined as the combination of a monitoring procedure, an assessment method and frequency, a reference point(s) and a harvest control rule. The monitoring procedure, assessment 
method and harvest control rule were the same in all runs, but the method of setting the management target and frequency of assessments varied as follows:

\section{Management strategies}

$$
\begin{gathered}
\text { F }_{\text {MSY }} \text { Proxy } \\
\mathrm{F}_{0.1} \\
\mathrm{~F}_{30 \% \mathrm{SPR}} \\
\mathrm{F}_{40 \% \mathrm{SPR}}
\end{gathered}
$$

$$
\begin{gathered}
\text { Assessment Frequency } \\
\text { (2) } \\
3 \text { year cycle } \\
\text { 1/4 generation time }
\end{gathered}
$$

Generation time is calculated as the average age of the spawning stock weighted by the spawning potential of each age when only natural mortality is acting, i.e. the sum of age (A) times the proportion surviving to that age $\left(\mathrm{S}_{\mathrm{A}}\right)$ times maturity at age $\left(\mathrm{M}_{\mathrm{A}}\right)$ times weight-at-age $\left(\mathrm{W}_{\mathrm{A}}\right)$, divided by the sum of survivors times maturity-at-age i.e.

$$
\frac{\sum A \times S_{A} \times M_{A} \times W_{A}}{\sum S_{A} \times M_{A} \times W_{A}}
$$

The stock/fishery scenarios considered aim to represent the combinations of life history characteristics, data availability and current stock status that may be encountered by ICCAT assessment working groups. They are defined by the 18 possible combinations of the following factors:

\section{Stock scenarios}

Stock

(3)

Northern Albacore

Atlantic Bigeye

\section{Current Status}

(3)

$0.125 \mathrm{~B}_{\text {Virgin }}{ }^{1}$ $0.375 \mathrm{~B}_{\text {Virgin }}$

East Atlantic Skipjack $0.615 \mathrm{~B}_{\text {Virgin }}$

${ }^{1} 0.250$ was used for skipjack because the value of 0.125 is incompatible with historical observations.

The combination of all possible management strategies and stock scenarios make 108 different treatments, all of which were run to allow the interactions to be investigated.

Model, estimation and measurement error were incorporated in the framework by explicitly modelling the assessment/management procedure. The management procedure is based upon VPA, a population model that reconstructs the stock history by making a backward projection assuming the total catch-at-age is known without error. It is also assumed that natural mortality and growth is constant and fixed. To initiate the backward projection the numbers- or fishing mortality-at-age of the oldest age in each cohort has to be estimated using catch per unit effort. In contrast, the operating model is a forward projection that includes process errors modelled as stochastic variations in natural mortality, recruitment, growth rate and selection. Therefore, the uncertainty in our ability to model the true system and to monitor catch, effort and biological data is explicitly included.

For each of the 108 combinations of treatments 100 replicate simulations were run, each associated with a random set of natural mortality, recruitment, growth and selection values.

The population and fleet parameters used in the experiments are presented in Appendix 1. Wherever possible the values used were the same as those used for the most recent assessment of each stock (ICCAT, 1999, 2000b and 2000c) and can be traced to comprehensive reviews of the biology of each stock (Bard, 1981; Bard and Capisano, 1991; Cayre et al., 1988; Fonteneau and Marcille, 1991). In some cases values have had to be assumed since data were not available.

\section{Analysis of performance}

To simplify the comparison of overall performance of individual management strategies it was decided to analyse only two performance statistics: $\mathrm{S}_{1}$, the ratio of SSB at the end of the rebuilding period to $\mathrm{B}_{\mathrm{MSY}}$; and $\mathrm{S}_{2}$, the ratio of mean yield over the rebuilding period to MSY. The former is a measure of the success of a strategy in achieving the objective of maintaining the biomass of the stock at a level that will support MSY, whilst the later indicates how close the catches were to MSY during the rebuilding period. In as much as 100 stochastic simulations were run for each combination of treatments, only the median result is shown. The medians were used because the rebuilding plan is essentially concerned with targets rather than limits. Aiming at a target infers that the intention of managers is to be at a particular value, so it seems appropriate to use a measure of central tendency like the median. In contrast, aiming at a limit infers that the managers are trying to avoid a value with high probability, so an appropriate statistic may be a 90 or 95 percentile.

To identify significant main effects and interactions, an analysis of variance was performed on the two summary statistics. A stepwise selection procedure (SPlus version 6, Insightful Corp.) using both forward and backwards selection was used to 
select significant terms as it was thought important that consistent methodology be applied across all stocks to select significant variables to aid in comparison. The resultant analyses of deviances are presented with tests for significance of the reported factors (marginal but non-significant factors are also included).

To compare the performance of management procedures across stocks and experimental treatments it is important to note the different starting status of exploitation of stocks at the beginning of the rebuilding period, as was shown at the beginning of the results section. A way to represent stock status is to show the yield prior to the start of the management procedure as a ratio of MSY $\left(\mathrm{S}_{3}\right)$ and the spawning stock biomass as a ratio of $\mathrm{SSB}_{\text {msy }}\left(\mathrm{S}_{4}\right)$. A stock is closer to the target of management the closer both ratios are to 1 . Note that, in our study, data were available up until 1997 and the first assessment was conducted in 1998. The year prior to the start of the procedure was therefore 1997.

\section{RESULTS}

The fishing mortality trends differ substantially between stocks. For albacore, overfishing $\left(F>F_{\text {msy }}\right)$ has occurred during the whole history of the data if depletion is set to 0.125 and intermittently if depletion is set to 0.375 . For bigeye, overfishing only occurs in the last few years when depletion is set to 0.125 . For skipjack there is never overfishing.
The spawning stock biomass trends differ between the stocks and depletion levels. For albacore the stock is overfished ( $\mathrm{SSB}<\mathrm{SSB}_{\text {msy }}$ ) for the greatest past of the history if depletion is set to 0.125 , but not overfished at all for the other depletion levels. For bigeye, the stock is only overfished in the most recent years and when depletion is set to 0.125 . For skipjack the stock is never overfished.

MSY estimates do not vary much for any stock within a depletion level, except for bigeye where a low observed catch in the mid 1980s changes the estimate substantially for a few years.

The stock recruitment relationships chosen exhibit strong compensation for bigeye and skipjack and weak compensation for albacore. As a result recruitment varied little in all the depletion scenarios for bigeye and skipjack, while for albacore there were substantial historical changes in recruitment, especially for depletion level 0.125 where recruitment has decreased by more than $50 \%$.

Table 1 summarises the proxies for $\mathrm{F}_{\mathrm{msy}}$, MSY and $\mathrm{B}_{\text {msy }}$ estimated at the start of the management procedure. For albacore and bigeye $\mathrm{F}_{40 \% \mathrm{SPR}}$ and $\mathrm{F}_{30 \% \mathrm{SPR}}$ respectively are closest to $\mathrm{F}_{\text {msy }}$ for all depletion levels and thus can be used to estimate $\mathrm{B}_{\text {msy }}$ and MSY rather accurately. For skipjack, all of the proxy reference points underestimate $\mathrm{F}_{\text {msy }}$ and overestimate $\mathrm{B}_{\text {msy }}$. However, all three proxies can be used to estimate MSY, although $\mathrm{F}_{30 \% \mathrm{SPR}}$ gives the best results.

For all species and depletion levels, estimates of MSY are less dependent on the proxy used than $B_{\text {msy }}$

TABLE 1. - A comparison of proxies for MSY based reference points.

\begin{tabular}{|c|c|c|c|c|c|c|c|c|c|}
\hline Albacore & $F_{M S Y}$ & $\begin{array}{l}0.125 \\
M S Y\end{array}$ & $B_{M S Y}$ & $F_{M S Y}$ & $\begin{array}{c}0.375 \\
M S Y\end{array}$ & $B_{M S Y}$ & $F_{M S Y}$ & $\begin{array}{c}0.625 \\
M S Y\end{array}$ & $B_{M S Y}$ \\
\hline $\begin{array}{l}\text { Actual } \\
F_{0.1} \\
F_{30 \% \text { SPR }} \\
F_{40 \% \text { SPR }}\end{array}$ & $\begin{array}{l}0.25 \\
0.50 \\
0.36 \\
0.27\end{array}$ & $\begin{array}{l}31486080 \\
37560399 \\
33562927 \\
29446637\end{array}$ & $\begin{array}{c}131996024 \\
53294963 \\
84495534 \\
112660714\end{array}$ & $\begin{array}{l}0.26 \\
0.53 \\
0.37 \\
0.28\end{array}$ & $\begin{array}{l}37177141 \\
54340154 \\
48309862 \\
42350145\end{array}$ & $\begin{array}{c}157388291 \\
75650740 \\
122949039 \\
163932050\end{array}$ & $\begin{array}{l}0.27 \\
0.55 \\
0.38 \\
0.29\end{array}$ & $\begin{array}{l}56664532 \\
91198088 \\
80808934 \\
70800335\end{array}$ & $\begin{array}{l}241308515 \\
125365428 \\
207055477 \\
276073880\end{array}$ \\
\hline Bigeye & $F_{M S Y}$ & $\begin{array}{c}0.125 \\
M S Y\end{array}$ & $B_{M S Y}$ & $F_{M S Y}$ & $\begin{array}{c}0.375 \\
M S Y\end{array}$ & $B_{M S Y}$ & $F_{M S Y}$ & $\begin{array}{c}0.625 \\
M S Y\end{array}$ & $B_{M S Y}$ \\
\hline $\begin{array}{l}\text { Actual } \\
F_{0.1} \\
F_{30 \% S P R} \\
F_{40 \% S P R}\end{array}$ & $\begin{array}{l}0.29 \\
0.21 \\
0.27 \\
0.20\end{array}$ & $\begin{array}{l}76264 \\
73577 \\
78203 \\
72585\end{array}$ & $\begin{array}{l}249192 \\
355591 \\
276635 \\
368847\end{array}$ & $\begin{array}{l}0.24 \\
0.17 \\
0.22 \\
0.17\end{array}$ & $\begin{array}{l}91449 \\
90508 \\
95962 \\
89089\end{array}$ & $\begin{array}{l}335564 \\
487229 \\
381529 \\
508705\end{array}$ & $\begin{array}{l}0.23 \\
0.17 \\
0.22 \\
0.16\end{array}$ & $\begin{array}{l}140771 \\
140890 \\
149230 \\
138466\end{array}$ & $\begin{array}{l}540449 \\
791646 \\
622573 \\
830098\end{array}$ \\
\hline Skipjack & $F_{M S Y}$ & $\begin{array}{c}0.250 \\
M S Y\end{array}$ & $B_{M S Y}$ & $F_{M S Y}$ & $\begin{array}{c}0.375 \\
M S Y\end{array}$ & $B_{M S Y}$ & $F_{M S Y}$ & $\begin{array}{c}0.625 \\
M S Y\end{array}$ & $B_{M S Y}$ \\
\hline $\begin{array}{l}\text { Actual } \\
F_{0.1} \\
F_{30 \% S P R} \\
F_{40 \% S P R}\end{array}$ & $\begin{array}{l}2.64 \\
1.13 \\
1.40 \\
0.92\end{array}$ & $\begin{array}{c}105786 \\
100602 \\
105798 \\
94347\end{array}$ & $\begin{array}{l}107616 \\
197086 \\
170306 \\
227075\end{array}$ & $\begin{array}{l}2.61 \\
1.14 \\
1.40 \\
0.92\end{array}$ & $\begin{array}{l}123118 \\
118251 \\
124299 \\
110841\end{array}$ & $\begin{array}{l}125757 \\
231464 \\
200261 \\
267015\end{array}$ & $\begin{array}{l}2.59 \\
1.14 \\
1.40 \\
0.92\end{array}$ & $\begin{array}{l}194073 \\
188832 \\
198372 \\
176885\end{array}$ & $\begin{array}{l}199195 \\
369224 \\
319943 \\
426590\end{array}$ \\
\hline
\end{tabular}


Example Projections of Yield

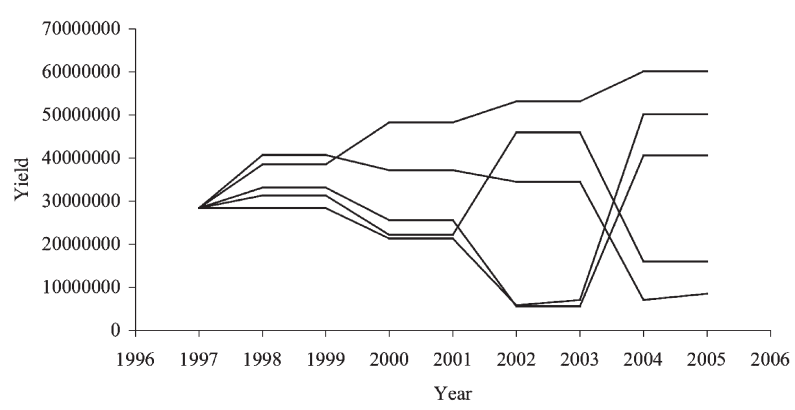

Example Projections of SSB

b)

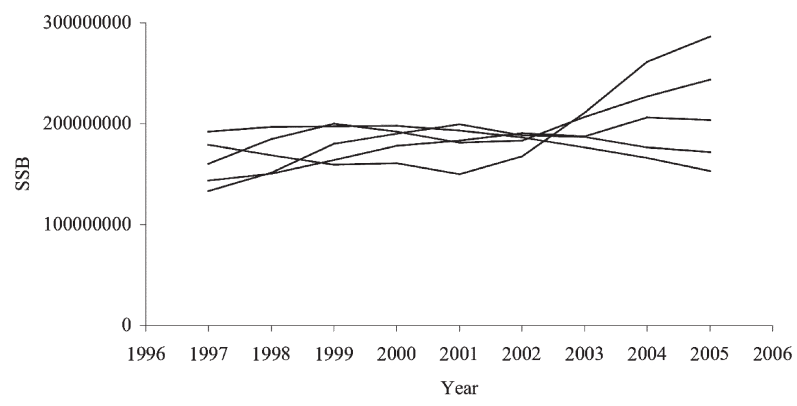

FIG. 4. - Examples of 5 model projections for albacore for selected simulations: a) yield, and b) spawning stock biomass.

or $\mathrm{F}_{\mathrm{msy}}$. The range of MSY values obtained from the different proxies varies by less than $25 \%$ for albacore and less than $12 \%$ for the other two species. $\mathrm{B}_{\mathrm{msy}}$ and $\mathrm{F}_{\mathrm{msy}}$ estimates obtained with different proxies, however, vary two or three times more than MSY estimates, probably because of the constant recruitment assumption used in their estimation. However, $\mathrm{F}_{\mathrm{msy}}$ was found to be much less sensitive to the assumption about the level of depletion than either MSY or $\mathrm{B}_{\mathrm{msy}}$.
In the simulations the management strategy is a "constant catch policy" where the total allowable catch (TAC) is updated every time the stock is reassessed. This then leads to increasing yield variation over time (Fig. 4a), but in contrast it ensures that the level of variation in spawning stock biomass remains constant over time (Fig. 4b). This strategy aims therefore to reduce risk by ensuring that spawning stock biomass remains within a prescribed range.

The analyses of variance of $S_{1}$, the ratio of $B$ at the end of the rebuilding period to $\mathrm{B}_{\mathrm{MSY}}$, and $\mathrm{S}_{2}$, the ratio of mean yield over the rebuilding period to MSY, were able to separate, for each species, the most significant factors determining the performance of management.

For albacore, the analysis of $\mathrm{S}_{1}$ indicated that the two most important factors for a successful management strategy were the carrying capacity of the stock and the proxy used for MSY (Table 2). Data quality and assessment frequency were also significant $(>5 \%)$ but not nearly as important as the previous two factors. The reason for the significant interaction between assessment frequency and carrying capacity was that, at the higher carrying capacity, a more frequent assessment policy resulted in the stock being closer to $\mathrm{B}_{\text {msy }}$ by the rebuilding year than it would have been with less frequent assessments. Analysis of $\mathrm{S}_{2}$ revealed only three significant effects, which in order of significance were: carrying capacity, MSY proxy, and the quality of the data.

The analysis of $\mathrm{S}_{1}$ for bigeye (Table 3 ) found that the most important effect was carrying capacity and the second was the proxy for MSY. There was a sig-

TABLE 2. - Albacore: Analysis of variance investigating significance of factors investigated for summary statistics, ratios of the SSB in the target rebuilding year to $\mathrm{B}_{\mathrm{MSY}}$ and mean yield over the rebuilding period to MSY.

\begin{tabular}{|c|c|c|c|c|c|c|}
\hline$S S B$ in Rebuilding Year: $B_{M S Y}$ & $D F$ & Deviance & Residual DF & Residual Deviance & $F$ Value & $P R>F$ \\
\hline NULL & & & 3598 & 1668.4 & & \\
\hline MSY Proxy & 2 & 105.6 & 3596 & 1562.8 & 162.2 & 0.0000 \\
\hline Assessment Frequency & 1 & 1.1 & 3595 & 1561.7 & 3.2 & 0.0719 \\
\hline Data Quality & 1 & 2.8 & 3594 & 1559.0 & 8.5 & 0.0036 \\
\hline Carrying capacity & 2 & 387.8 & 3592 & 1171.2 & 595.7 & 0.0000 \\
\hline Assessment Frequency : Carrying capacity & 2 & 2.5 & 3590 & 1168.7 & 3.8 & 0.0219 \\
\hline Mean Yield over rebuilding period: $M S Y$ & $D F$ & Deviance & Residual DF & Residual Deviance & $F$ Value & $P R>F$ \\
\hline$N U L L$ & & & 3598 & 1670.0 & & \\
\hline MSY Proxy & 2 & 119.7 & 3596 & 1550.3 & 162.0 & 0.0000 \\
\hline Data Quality & 1 & 4.8 & 3595 & 1545.4 & 13.1 & 0.0003 \\
\hline Carrying capacity & 2 & 217.5 & 3593 & 1327.9 & 294.3 & 0.0000 \\
\hline
\end{tabular}


TABLE 3. - Bigeye: Analysis of variance investigating significance of factors investigated for summary statistics, ratios of the SSB in the target rebuilding year to $\mathrm{B}_{\mathrm{MSY}}$ and mean yield over the rebuilding period to MSY.

\begin{tabular}{lrrrrrr}
\hline SSB in Rebuilding Year: $B_{M S Y}$ & DF & Deviance & Residual DF & Residual Deviance & $F$ Value & PR $>F$ \\
\hline NULL & & & 3958 & 4785,9 & \\
MSY Proxy & 2 & 99,7 & 3956 & 4686,2 & 64,4 & 0,0000 \\
Data Quality & 1 & 0,2 & 3955 & 4686,0 & 0,3 & 0,5907 \\
Carrying capacity & 2 & 1615,0 & 3953 & 3071,0 & 1043,3 & 0,0000 \\
DataQuality :Carrying Capacity & 2 & 12,9 & 3951 & 3058,1 & 8,4 & 0,0002 \\
\hline Mean Yield over rebuilding period : MSY & DF & Deviance & Residual DF & Residual Deviance & $F$ Value & PR $>$ F \\
\hline NULL & & & 3958 & 637,1 & \\
MSY Proxy & 2 & 4,7 & 3956 & 632,4 & 18,4 & 0,0000 \\
Data Quality & 1 & 9,5 & 3955 & 622,9 & 74,2 & 0,0000 \\
Carrying capacity & 2 & 113,6 & 3953 & 509,3 & 444,8 & 0,0000 \\
Data Quality :Carrying Capacity & 2 & 4,8 & 3951 & 504,5 & 18,8 & 0,0000 \\
& & & & &
\end{tabular}

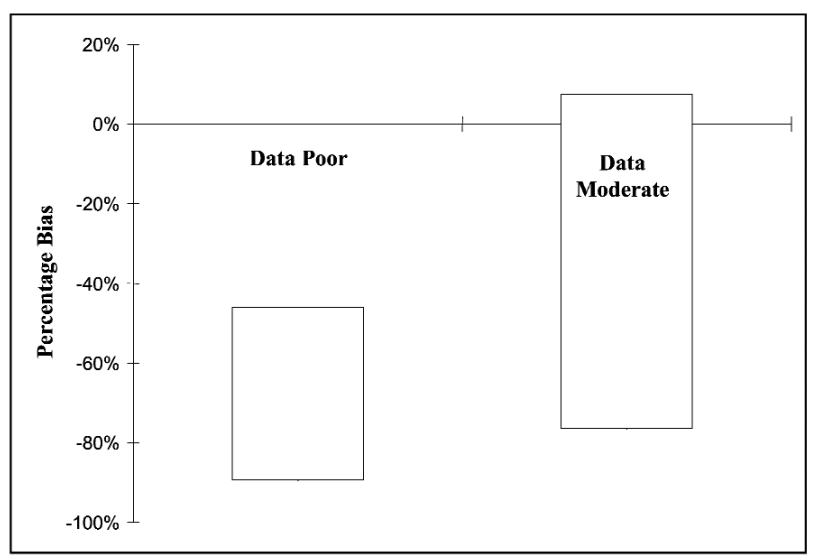

FIG. 5. - Bias in final year biomass estimated by the assessment model for a data rich and a data poor case for albacore. Boxes show the interquartile range for (estimated-true)/true.

nificant interaction between data quality and carrying capacity. The reason for the interaction was the greater bias in assessment based on the data poor than the data rich set. It should be noted that the effect of improving the data is not to increase precision but to reduce bias (Fig. 5). The analysis of $\mathrm{S}_{2}$ only found three main effects to be significant, which, in order of significance, were carrying capac- ity, data quality, and the proxy used for MSY. In addition, there was a significant interaction between data quality and carrying capacity. This interaction occurred because bias was greater for the stock with the greatest carrying capacity.

Only carrying capacity and proxy for MSY were found to be significant in the analysis of $S_{1}$ for skipjack (Table 4). Three significant effects were found in the analysis of $\mathrm{S}_{2}$ for skipjack, in order of significance these were proxy for MSY, carrying capacity and data quality. There were no significant interactions.

For stocks with high carrying capacities the stock is initially less likely to be overfished. In general, the most important factor for maintaining the stock at $\mathrm{B}_{\text {msy }}$ was the carrying capacity of the stock, followed by the proxy used to determine $\mathrm{B}_{\text {msy }}$. These factors represent the dynamics of the stock over the long time scale. These factors were also important in determining mean yield, since management was set relative to the estimates of the two factors. Data quality was also important in determining mean yield. The stock assessment method used was VPA as implemented in ADAPT. Since the stock dynamics

TABLE 4. - Skipjack: Analysis of variance investigating significance of factors investigated for summary statistics, ratios of the SSB in the target rebuilding year to $\mathrm{B}_{\mathrm{MSY}}$ and mean yield over the rebuilding period to MSY.

\begin{tabular}{|c|c|c|c|c|c|c|}
\hline$S S B$ in Rebuilding Year: $B_{M S Y}$ & $D F$ & Deviance & Residual DF & Residual Deviance & $F$ Value & $P R>F$ \\
\hline$N U L L$ & & & 3551 & 3563,9 & & \\
\hline MSY Proxy & 2 & 37,4 & 3549 & 3526,5 & 20,3 & 0,0000 \\
\hline Carrying capacity & 2 & 251,2 & 3547 & 3275,3 & 136,0 & 0,0000 \\
\hline Mean Yield over rebuilding period : MSY & $D F$ & Deviance & Residual DF & Residual Deviance & $F$ Value & $P R>F$ \\
\hline NULL & & & 3551 & 889,2 & & \\
\hline MSY Proxy & 2 & 43,7 & 3549 & 845,4 & 92,5 & 0,0000 \\
\hline Data Quality & 1 & 1,0 & 3548 & 844,4 & 4,4 & 0,0364 \\
\hline Carrying capacity & 2 & 6,0 & 3546 & 838,4 & 12,7 & 0,0000 \\
\hline
\end{tabular}



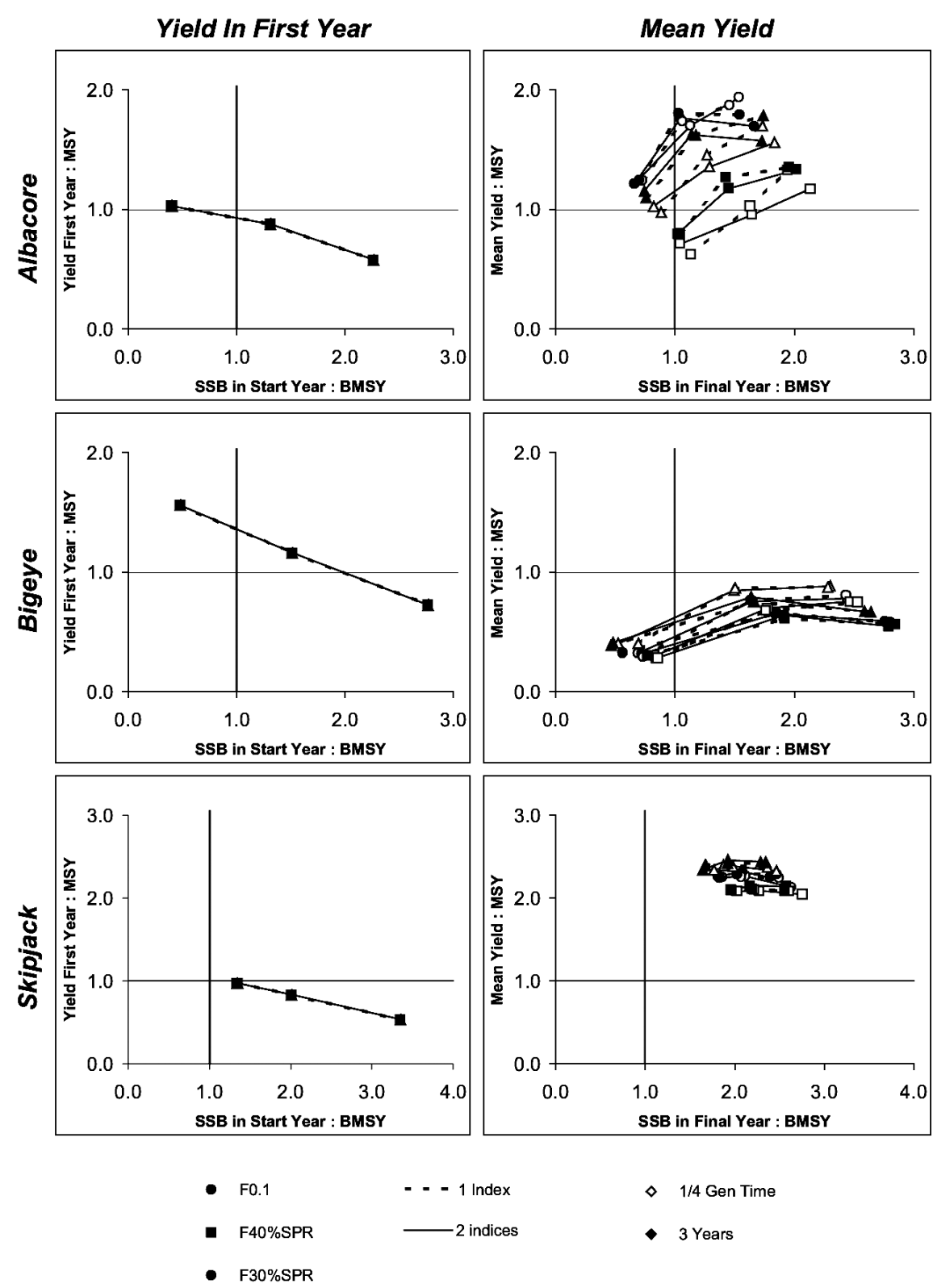

FIG. 6. - Performance of a management procedure for three tuna stocks as a function of the different treatment scenarios. Left hand panels represent the status of the stock at the beginning of the procedure, and the right hand panels the status as a result of the procedure measured by the mean yield during the procedure and the SSB at the end of the procedure. All values are relative ratios of the MSY and SSB msy $_{\text {tar- }}$ gets. The shape of the symbol represents the type of proxy used, circles $\mathrm{F}_{0.1}$, triangles $\mathrm{F}_{30 \% \mathrm{SPR}}$ and squares $\mathrm{F}_{40 \% \mathrm{SPR}}$. The colour of the symbol represents data quality, solid for two indices and open for one index. Lines connect treatments that are identical apart from the carrying capacity. The type of line represents the assessment cycle, hatched for every three years, solid for every $1 / 4$ of a lifespan. The reference lines parallel to the $\mathrm{x}$ - and $\mathrm{y}$-axes correspond to the MSY and $\mathrm{B}_{\mathrm{MSY}}$ levels respectively.

of the assessment model and the operating model were similar, the convergence properties of VPA means that population estimates made by the assessment procedure are more uncertain in the recent period than in the long term. Setting yield is more influenced by short-term considerations whilst maintaining the stock at a level that will support MSY is more dependent on long-term considerations.

In summary, it is apparent that albacore, bigeye and skipjack are in a gradient from more to less like- ly to be overfished in the initial year of the management procedure (Fig. 6). The management procedure only worked well for albacore but depended on the $\mathrm{F}_{40 \%}$ proxy chosen. For this species, if the stock was overfished, it recovered within one lifespan, and if the stock was underfished, it was able to increase yields and maintain SSB above $\mathrm{SSB}_{\text {msy }}$. For bigeye, the procedure failed completely since if the stock was overfished it did not recover within one lifespan, and if it was underfished, it was unable to 
increase yields. In fact, if the fishery was catching the target MSY level the procedure reduced catches below MSY. This effect could be just due to the presence of uncertainty in population parameters (process uncertainty). For skipjack, the procedure succeeded in reaching the targets as it allowed increases in yield and maintained SSB above $\mathrm{SSB}_{\text {msy. }}$. It could, however, be argued that if the goal of the skipjack fishery was to maximise yield whilst complying with the target, the management procedure failed by being too conservative and not allowing large enough increases in yield over the period of one lifespan.

\section{DISCUSSION}

Our study used ICCAT stocks as case studies; however, many of the conclusions of this study are likely to be relevant for other tuna stocks because the ICCAT management structure is representative of the structure of other international tuna commissions (Ward et al., 2000). The management procedure selected in this study did not perform equally well for the three different stocks. This suggests that management strategies must be designed taking into account the biological characteristics of each specific tuna stock; it also suggests that a single strategy is unlikely to be appropriate for all ICCAT managed stocks (a conclusion also reached by Fromentin and Fonteneau, in press). In fact, such a management procedure may be too conservative for fast growing tunas like skipjack.

The performance of the management strategy was most sensitive to the carrying capacity of the stock and the type of proxy chosen as a reference point. The final status of the spawning stock and the yield stream obtained during the application of the strategy differed markedly, depending on the initial condition of the stock. The latter is not a surprising result because the procedure was not designed to produce an average level of yield but rather to drive this yield towards MSY. Also depending on the starting point, the average yield during the procedure would differ. The fact that the spawning stock at the end of one lifespan was so sensitive to the initial condition of the stock suggests that the procedure does not truly achieve its goal of achieving a target biomass, rather it operates as if $\mathrm{B}_{\mathrm{msy}}$ was a limit indicator. In fact, it is unclear why the strategy performed poorly at rebuilding B, but relatively well at reaching MSY. In some cases, the choice of refer- ence point also affected performance. This highlights how the framework can reveal the real behaviour of a procedure. It also shows how important for the development of an appropriate management procedure it is to reduce the uncertainty about the current status of a stock, and its natural fluctuations over time (see e.g. Hjort 1914, Cushing 1982), and to determine the appropriate reference point for use during the assessment.

The type of assessment process does affect the strategy, but it seems that the type of proxy used for $\mathrm{F}_{\mathrm{msy}}$ is more important than the frequency of assessments, so it is probably more productive to determine the right proxy to be used for a stock rather than to increase the frequency of assessments. This highlights how the framework developed can be used to determine the right balance between investment in tactical (periodic assessments) versus strategic research (development of assessment methods).

Our results suggest that the availability of more data tends to reduce bias rather than increase precision. This is an interesting result in light of the difficulty in obtaining fishery independent data for tunas. One of the advantages of fishery independent data is the reduction in biases, but our results suggest that such reduction may also be obtained through the use of more fishery dependent indices. It is important to note that it is not possible to say whether this sort of result reflects only these stocks and fisheries or if it is fairly general for all fisheries.

The current study has many limitations, including the fact that it only considers one type of management control. There are certainly many other types of controls that could be investigated with this framework, including constant catch strategies, or strategies that allow greater changes in catch between assessment cycles. Another limitation of this work is that it did not consider all the uncertainties present in the real world, some of which have been shown to affect the results of stock assessments. Examples of these effects are mis-reporting of catch (Fromentin, 2003), bias in estimates of biological parameters (Majkowski and Hampton, 1983; Bradford and Peterman, 1989; Tanaka, 1989; Clark, 1999; Hampton, 1999, Kell et al., 1999), uncertainty with catch-at-age data because of ageing errors (Tyler et al., 1989; Bradford, 1990; Beamish and McFarlane, 1995, Kell et al., 2000) or because of the conversion from length to age through length slicing, and historic trends in population parameters.

Our framework only considers performance indicators related to the target species and ignores the 
importance of other factors such as the effects of fishing on humans or on components of the environment other than the target species (Garcia et al., 2000). Although it is clear that some of these factors are extremely important in the management of tunas, incorporating them into the simulation framework would require expanding of the operating and assessment models to include components of the fishery system that are presently very difficult to characterise quantitatively.

This research shows, like other studies (Ulltang, 1996), that the performance of the strategy was more dependent on the type of control (specifically the type of proxy used in the harvest control rule) than on the quality of the estimates of stock status. However, it remains to be seen whether this result depends on the fact that we only evaluated a constant catch strategy. Although much work has focused on estimation error that arises from trying to model the dynamic process during the assessment process, more work is needed to evaluate the robustness of current stock assessment and management procedures. In particular, attention should be given to the natural variation in dynamic processes, the error generated when collecting observations from a population, and error in implementing management actions.

This study aimed to elucidate general guidelines about assessment and management for a range of tuna stocks with different life histories before undertaking more detailed stock specific studies. The effects of many of these uncertainties on the performance of the management procedure for specific tuna fisheries will be investigated in the future with the framework. In particular, research will be carried out on the consequences of errors in catch and effort estimates induced by the response of fishing fleets to management, the effects of temporal trends in stock dynamics, the robustness of current practice to migration or movement of a stock across stock boundaries, and the problems created by spatial heterogeneity in tuna stocks. All this work will lead towards the development of general strategies based on life histories for stocks where data are limited.

\section{ACKNOWLEDGEMENTS}

This research was carried out in part under the auspices of the Cooperative Institute of Marine Atmospheric Studies, a Joint Institute of the University of Miami and the National Oceanographic
Atmospheric Administration, cooperative agreement \#NA67RJ0149. The research also builds upon the work done by the ICCAT working groups on Albacore, and tropical tunas. Gerry Scott, Clay Porch and Manoj Shivlani provided invaluable comments to an earlier version of this manuscript.

\section{REFERENCES}

Bard, F.X. - 1981. Le thon germon Thunnus alalunga (Bonaterre 1788) de l'océan atlantique. Thèse de Doctorat d'Etat, Université Pierre et Marie Curie, Paris.

Bard, F.X. and C. Capisano. - 1991. Actualisation des connaissances sur la reproduction de 1'albacore (Thunnus alalunga) en océan atlantique. ICCAT Scient. Pap. 36, 182-204.

Beamish, R.J. and G.A. McFarlane. - 1995. A Discussion of the importance of ageing errors, and application to walleye pollock: the world's largest fishery. In: D.H. Sector, S. E. Campana and J.M. Dean (eds.), Recent developments in fish otolith research. University of South Carolina Press, Columbia, South Carolina.

Bradford, M.J. - 1991. Effects of ageing errors on recruitment time series estimated from sequential population analysis. Can. J. Fish. Aquat. Sci., 48: 555-558.

Bradford, M.J. and R.M. Peterman. - 1989. Incorrect parameter values used in virtual population analysis (VPA) generate spurious time trends in reconstructed abundances. Can. Spec. Publ. Fish. Aquat. Sci., 108: 87-99.

Cayré, P., J.B. Amon Kothias, J.M. Stretta and T. Diouf. - 1988. Biologie des thons. In: A. Fonteneau and J. Marcille. (eds), Ressources, pêche et biologie des thonidés tropicaux de l'Atlantique centre-est, pp. 157-268. FAO Doc. Tech. Pêches 292, Rome.

Clark, W.G. - 1999. Effects of an erroneous natural mortality rate on a simple age-stuctured stock assessment. Can. J. Fish. Aquat. Sci., 56: 1721-1731

Cushing, D.H. - 1982. Climate and fisheries. Academic Press, London.

De la Mare, W.K. - 1998. Tidier fisheries management requires a new MOP (management-oriented paradigm). Rev. Fish Biol. Fish., 8: 349-356.

Doulman, D.J. - 1995c. Structure and Process of the 1993-1995 United Nations Conference on Straddling Fish Stocks and Highly Migratory Fish Stocks. FAO Fish. Circ., No.898.

FAO. - 1996. Precautionary Approach to Fisheries. FAO Technical Paper 350/1.

FAO. - 1995. Code of Conduct for Responsible Fisheries. Rome, FAO. 41 pp.

Fonteneau, A. and J. Marcille (eds.). - 1991. Recursos, pesca y biologia de los tunidos tropicales del Atlantico centro Oriental. ICCAT, 423 pp.

Francis, R.I.C.C. - 1992. Use of risk analysis to assess fishery management strategies: A case study using orange roughy (Hoplostethus atlanticus) on the Chatham Rise, New Zealand. Can. J. Fish. Aquat. Sci., 49: 922-930.

Fromentin, J.M. - 2003. The East Atlantic and Mediterranean bluefin tuna stock management: uncertainties and alternatives. Sci. Mar., 67(Suppl. 1): 51-62

Fromentin, J.M, and A. Fonteneau. - (In press). Fishing effects and life history traits: a case study comparing tropical versus temperate tunas, Fish. Res.

Fromentin, J.M, A. Fonteneau and H. Farrugio. - 1999. Biological reference points and natural long-term fluctuations: The case of the eastern Atlantic bluefin tuna. ICCAT working document. SCRS/99/54.

Garcia, S.M., D.J. Staples and J. Chesson. - 2000. The FAO guidelines for the development and use of indicators for sustainable development of marine capture fisheries and an Australian example of their application. Ocean Coast. Manage., 43: 537556.

Hampton, J. - 2000. Natural mortality rates in tropical tunas: size really does matter. Can. J. Fish. Aquat. Sci., 57: 1002-1010.

Hjort, J. - 1914. Fluctuations in the great fisheries of northern 
Europe. Viewed in the light of biological reseach. Rapp. P.-v Reun. Cons. int. Explor. mer, 20: 1-228.

Holt, S. - 1998. Fifty years on. Rev. Fish Biol. Fish., 8: 357-366.

ICCAT. - 1999a. Report of the Meeting of the ICCAT Ad Hoc Working Group on Precautionary Approach (Dublin, Ireland, May 17-21, 1999). SCRS/99/11

ICCAT. - 1999b. SRCS Detailed Report on Albacore. ICCAT, Col. Doc.Sci, vol XLX (1).

ICCAT. - 2000a. SCRS detailed Report on Bigeye. ICCAT, Col. Doc. Sci. vol LI. pp. 1-88.

ICCAT. - 2000b. SCRS detailed Report on Skipjack. ICCAT, Col. Doc. Sci. vol LI. pp. 132-220.

ICES. - 1994. Report of the Working Group on Long-term Management Measures. ICES CM 1994/Assess: 11.

Kell, L.T., C.M. O'Brien, M.T. Smith, T.K. Stokes, and B.D. Rackham. - 1999a. An evaluation of management procedures for implementing a precautionary approach in the ICES context for North Sea plaice Pleuronectes platessa L. ICES J. Mar. Sci., 56: $834-845$.

Kell, L.T., J.M. Fromentin, F. Gauthiez and V.R. Restrepo. 1999b. A simulation framework to evaluate management strategies for Atlantic tunas: a preliminary example based on East Atlantic bluefin tuna. ICCAT working document. SCRS/99/11 $2095-2116$

Legault, C.M. and V.R. Restrepo. - 1998. A flexible forward agestuctured assessment program. ICCAT working document. SCRS 98/58. $15 \mathrm{pp}$
Majkowski, J. and J. Hampton. - 1983. The effect of parameter uncertainties in an age-length relationship upon estimating the age composition of catches. Can. J. Fish. Aquat. Sci., 40: 272-280.

Powers, J.E. and V.R. Restrepo. - 1992. Additional options for agesequenced analysis. Collect. Vol. Sci. Pap. ICCAT., 39: 540-553.

Rosenberg, A.A., M.J. Fogarty, M.P. Sissenwine, J.R., Beddington and J.G. Shepherd. - 1993. Achieving sustainable use of renewable resources. Science, 262: 828-829.

Rosenberg, A.A. and Restrepo, V.R. - 1995. Uncertainty and risk evaluation in stock assessment advice for U.S. marine fisheries. Can. J. Fish. Aquat. Sci., 51: 2715-2720.

Tanaka, S. - 1989. Influence of errors in parameter estimates on stock assessment. Can. Spec. Publ. Fish. Aquat. Sci., 108: 37-42.

Tyler, A.V., R.J. Beamish and G.A. McFarlane. - 1989. Implications of Age determination errors to yield estimates. Can. Spec. Publ. Fish Aquat. Sci., 108: 27-35.

Ulltang, O. - 1996. Stock assessment and biological knowledge: can prediction uncertainty be reduced? ICES J. Mar. Sci., 53: 659-675.

Walters, C.J. - 1986. Adaptive management of renewable resources. MacMillan Publishing, New York.

Ward, P., B. Kearney and N. Tsirbas. - 2000. Science arrangements for the regional management of tuna fisheries. Mar. Policy., 24: 93-108.

Wilimovsky, N.J. - 1985. The need for formalization of decision algorithms and risk levels in fishery research and management. Can. J. Fish. Aquat. Sci., 42: 258-262.

\section{APPENDIX 1. DETAILS OF PARAMETERS USED IN THE FMSE SIMULATIONS.}

\section{Fleet parameters}

Wherever possible four fleets were modelled for each stock: purse seine, long line, bait boat and another, which could be a fleet peculiar to a particular stock or else an aggregation of various fleets.

To make comparisons between stocks easier it was decided to have two indices of abundance per stock, so that both younger and older ages were represented. However, similar indices are not available for all the four stocks, as often indices are missing for particular age ranges and appropriate fleets. If more than two suitable indices were available, only two were chosen. If suitable indices did not exist for a particular fleet then indices were either generated by substituting an index for another fleet that fished on a similar age range or else by making assumptions about catch and effort trends. All indices are in numbers rather than biomass and were converted from biomass using catch- and weight-at-ages where necessary.

\section{Albacore}

The fleets used in the albacore simulation were long line, bait boat, troll and another. Selection pat-

Table 5. - Selection Pattern used in operating model

\begin{tabular}{|c|c|c|c|c|c|c|c|c|c|c|c|c|}
\hline \multirow{2}{*}{$\frac{\text { Age }}{1}$} & \multirow{2}{*}{$\begin{array}{c}\text { Bait boat } \\
0.4169\end{array}$} & \multirow{2}{*}{$\begin{array}{c}\begin{array}{c}\text { Albacore } \\
\text { Long line }\end{array} \\
0.0069\end{array}$} & \multirow{2}{*}{$\begin{array}{c}\text { Troll } \\
0.2586\end{array}$} & \multirow{2}{*}{$\begin{array}{l}\text { Other } \\
0.1175\end{array}$} & \multirow{2}{*}{$\frac{\text { Age }}{0}$} & \multirow{2}{*}{$\begin{array}{c}\text { Bait boat } \\
0.6225\end{array}$} & \multicolumn{2}{|c|}{$\begin{array}{l}\text { Bigeye } \\
\text { Long linePurse seine }\end{array}$} & \multirow{2}{*}{$\frac{\text { Age }}{0}$} & \multirow{2}{*}{$\begin{array}{c}\text { Bait boat } \\
0.0355\end{array}$} & \multicolumn{2}{|c|}{$\begin{array}{l}\text { Skipjack } \\
\text { Long line Purse seine }\end{array}$} \\
\hline & & & & & & & 0.0010 & 1.0000 & & & 0.0841 & 0.0598 \\
\hline 2 & 0.8666 & 0.0256 & 1.0000 & 1.0000 & 1 & 1.0000 & 0.0210 & 0.7251 & 1 & 1.0000 & 1.0000 & 1.0000 \\
\hline 3 & 1.0000 & 0.4021 & 0.6411 & 0.5581 & 2 & 0.7164 & 0.1970 & 0.4501 & 2 & 0.5086 & 0.3124 & 0.4105 \\
\hline 4 & 0.2972 & 0.7179 & 0.1030 & 0.2343 & 3 & 0.4178 & 0.6190 & 0.2404 & 3 & 0.4544 & 0.2440 & 0.3492 \\
\hline 5 & 0.0707 & 1.0000 & 0.0188 & 0.1985 & 4 & 0.2015 & 1.0000 & 0.1438 & 4 & 0.4544 & 0.2440 & 0.3492 \\
\hline 6 & 0.0832 & 0.8875 & 0.0116 & 0.4346 & 5 & 0.1072 & 0.9260 & 0.1310 & 5 & 0.4544 & 0.2440 & 0.3492 \\
\hline 7 & 0.1519 & 0.8484 & 0.0138 & 0.7372 & 6 & 0.0594 & 0.6130 & 0.0968 & 6 & 0.4544 & 0.2440 & 0.3492 \\
\hline \multirow[t]{5}{*}{8} & 0.1893 & 0.9069 & 0.0088 & 0.6379 & 7 & 0.0551 & 0.6760 & 0.0105 & 7 & 0.4544 & 0.2440 & 0.3492 \\
\hline & & & & & 8 & 0.0551 & 0.6760 & 0.0105 & 8 & 0.4544 & 0.2440 & 0.3492 \\
\hline & & & & & 9 & 0.0551 & 0.6760 & 0.0105 & 9 & 0.4544 & 0.2440 & 0.3492 \\
\hline & & & & & 10 & 0.0551 & 0.6760 & 0.0105 & 10 & 0.4544 & 0.2440 & 0.3492 \\
\hline & & & & & 11 & 0.0551 & 0.6760 & 0.0105 & 11 & 0.4544 & 0.2440 & 0.3492 \\
\hline
\end{tabular}


TABLE 6. - Historical series of yield used in operating model

\begin{tabular}{|c|c|c|c|c|c|c|c|c|c|c|c|c|}
\hline \multirow{3}{*}{$\begin{array}{l}\text { Year } \\
1975\end{array}$} & \multicolumn{2}{|c|}{ Albacore } & \multirow[b]{2}{*}{ Troll } & \multirow[b]{2}{*}{ Other } & \multirow[b]{2}{*}{ Year } & \multicolumn{2}{|c|}{$\begin{array}{l}\text { Bigeye } \\
\text { Bait }\end{array}$} & \multirow[b]{2}{*}{ Purse seine } & \multirow[b]{2}{*}{ Year } & \multirow{2}{*}{\multicolumn{2}{|c|}{$\begin{array}{l}\text { Skipjack } \\
\text { Bait boat Long line }\end{array}$}} & \multirow{2}{*}{ Purse seine } \\
\hline & Bait boat & Long line & & & & Bait boat & Long line & & & & & \\
\hline & 17898752 & 10040400 & 9957222 & 5266524 & 1979 & 9591 & 27560 & 8824 & 1975 & 15095 & 19776 & 2386 \\
\hline 1976 & 19750939 & 16657354 & 15077057 & 9181592 & 1980 & 12349 & 41678 & 9793 & 1976 & 26382 & 24831 & 4307 \\
\hline 1977 & 15200661 & 15014529 & 18353465 & 7389131 & 1981 & 10124 & 41608 & 16454 & 1977 & 34734 & 44502 & 9905 \\
\hline 1978 & 11186419 & 10153205 & 24312955 & 5156415 & 1982 & 6922 & 52026 & 14763 & 1978 & 39365 & 48694 & 4826 \\
\hline 1979 & 16588059 & 8760365 & 24383801 & 4870286 & 1983 & 9796 & 33648 & 15833 & 1979 & 27560 & 8343 & 9591 \\
\hline 1980 & 15729941 & 8433420 & 13106211 & 1882265 & 1984 & 11439 & 41599 & 16301 & 1980 & 41678 & 9204 & 12349 \\
\hline 1981 & 12238526 & 8951480 & 11194713 & 2569742 & 1985 & 17651 & 48810 & 7757 & 1981 & 41608 & 15656 & 10124 \\
\hline 1982 & 15286446 & 12315552 & 13009548 & 3074923 & 1986 & 15618 & 36796 & 9680 & 1982 & 52026 & 14476 & 6922 \\
\hline 1983 & 18718277 & 16092773 & 13042920 & 4346404 & 1987 & 12631 & 3222 & 7734 & 1983 & 33648 & 15654 & 9796 \\
\hline 1984 & 7069615 & 16724160 & 11136389 & 6950041 & 1988 & 9710 & 45541 & 8273 & 1984 & 41599 & 16063 & 11439 \\
\hline 1985 & 11261641 & 17212216 & 10231739 & 3056898 & 1989 & 12672 & 55098 & 6964 & 1985 & 48810 & 7554 & 17651 \\
\hline 1986 & 13996768 & 21410118 & 10960563 & 2077741 & 1990 & 18106 & 51333 & 9703 & 1986 & 36796 & 9286 & 15618 \\
\hline 1987 & 16971719 & 7338482 & 11360235 & 1356888 & 1991 & 17750 & 61393 & 16588 & 1987 & 3222 & 7148 & 12631 \\
\hline 1988 & 14975989 & 2947807 & 10691585 & 3373012 & 1992 & 16248 & 62271 & 17995 & 1988 & 45541 & 7859 & 9710 \\
\hline 1989 & 14307712 & 1987595 & 10883586 & 4662522 & 1993 & 16467 & 62815 & 30289 & 1989 & 55098 & 6371 & 12672 \\
\hline 1990 & 15608196 & 2436720 & 10512211 & 9015831 & 1994 & 20296 & 77885 & 31364 & 1990 & 51333 & 9407 & 18106 \\
\hline 1991 & 8547369 & 5146809 & 9598768 & 6098818 & 1995 & 25552 & 74000 & 25347 & 1991 & 61393 & 16169 & 17750 \\
\hline 1992 & 10564626 & 2901667 & 7707697 & 9821929 & 1996 & 19040 & 73660 & 26799 & 1992 & 62271 & 17467 & 16248 \\
\hline 1993 & 12254428 & 7567995 & 6506703 & 14708150 & 1997 & 18721 & 66619 & 17551 & 1993 & 62815 & 29676 & 16467 \\
\hline 1994 & 11689478 & 7379463 & 6257867 & 12048301 & & & & & 1994 & 77885 & 30434 & 20296 \\
\hline 1995 & 9671020 & 4532638 & 10883094 & 15037840 & & & & & 1995 & 74000 & 24786 & 25552 \\
\hline 1996 & 9395450 & 4128840 & 6952839 & 8494614 & & & & & 1996 & 73660 & 26446 & 19040 \\
\hline 1997 & 9617038 & 3620043 & 8195789 & 7022856 & & & & & 1997 & 66619 & 17037 & 18721 \\
\hline
\end{tabular}

terns (Table 5) were derived using the most recent selectivities patterns from the 1998 ASAP assessment (ICCAT, 1999). The indices of abundance used were Japanese long line ages 1 to 7 and Spanish trollers ages 2 and 3. Indices of abundance for the long line and other fleets were generated from these series by first calculating a relative effort measure and dividing the observed catches by the relevant index.

\section{Bigeye}

The fleets used in the bigeye simulation were purse seine, long line, bait boat and another. Selection patterns were derived from the partial Fs for the period 1991-1998 using a general selection pattern obtained by separable VPA (ICCAT, 2000a). The indices of abundance used were Japanese long line all ages and US long line ages 2 to 5. The US long line index is an index of abundance for ages 2 to 5 and so was used to substitute for a bait boat index where the maximum selectivity is at age 4 . In this way indices of abundance were generated for the long line and the bait boat series by calculating a relative effort measure and dividing the observed catches by the relevant index.

\section{Skipjack}

The fleets used in the skipjack simulation were purse seine, long line, baitboat and another. Model parameters were obtained from ICCAT (2000b) when possible. Some parameters, however, were not

TABLE 7. - Biological parameter vectors used in operating model

\begin{tabular}{|c|c|c|c|c|c|c|c|c|}
\hline Age & \multicolumn{2}{|c|}{ Albacore } & Age & Bigeye & Maturity & Age & \multicolumn{2}{|c|}{ Skipjack } \\
\hline 1 & 0.3 & 0.0 & 0 & 0.80 & 0.00 & 0 & 0.80 & 0.00 \\
\hline 2 & 0.3 & 0.0 & 1 & 0.80 & 0.00 & 1 & 0.80 & 0.75 \\
\hline 3 & 0.3 & 0.0 & 2 & 0.40 & 0.00 & 2 & 0.80 & 1.00 \\
\hline 4 & 0.3 & 0.0 & 3 & 0.40 & 0.50 & 3 & 0.80 & 1.00 \\
\hline 5 & 0.3 & 0.5 & 4 & 0.40 & 1.00 & 4 & 0.80 & 1.00 \\
\hline 6 & 0.3 & 1.0 & 5 & 0.40 & 1.00 & 5 & 0.80 & 1.00 \\
\hline 7 & 0.3 & 1.0 & 6 & 0.40 & 1.00 & 6 & 0.80 & 1.00 \\
\hline 8 & 0.3 & 1.0 & 7 & 0.40 & 1.00 & 7 & 0.80 & 1.00 \\
\hline 9 & 0.3 & 1.0 & 8 & 0.40 & 1.00 & 8 & 0.80 & 1.00 \\
\hline 10 & 0.3 & 1.0 & 9 & 0.40 & 1.00 & 9 & 0.80 & 1.00 \\
\hline 11 & 0.3 & 1.0 & 10 & 0.40 & 1.00 & 10 & 0.80 & 1.00 \\
\hline 12 & 0.3 & 1.0 & 11 & 0.40 & 1.00 & 11 & 0.80 & 1.00 \\
\hline
\end{tabular}


TABLE 8. - Growth (Von Bertalanffy) parameters used in operating model

\begin{tabular}{|c|c|c|c|c|c|}
\hline \multicolumn{2}{|c|}{ Albacore } & \multicolumn{2}{|c|}{ Bigeye } & \multicolumn{2}{|c|}{ Skipjack } \\
\hline $\operatorname{Linf}$ & 124.74 & $\operatorname{Linf}$ & 285.37 & $\operatorname{Linf}$ & 80 \\
\hline$K$ & 0.23 & $K$ & 0.11 & $K$ & 0.3 \\
\hline to & -0.9892 & to & -0.5 & to & -0.6 \\
\hline Cond Fact & 1.3E-05 & Cond Fact & 2.4E-05 & Cond Fact & $7.5 \mathrm{E}-06$ \\
\hline Power & 3.107 & Power & 2.98 & Power & 3.253 \\
\hline$C V$ & & $C V$ & 0.00 & $C V$ & 0.00 \\
\hline \multicolumn{2}{|c|}{ Instantaneous time of } & \multicolumn{2}{|c|}{ Instantaneous time of } & \multicolumn{2}{|c|}{ Instantaneous time of } \\
\hline Spawning & 0.5 & Spawning & 0.0 & Spawning & 0.5 \\
\hline Capture & 0.5 & Capture & 0.5 & Capture & 0.5 \\
\hline
\end{tabular}

available for this species and were obtained from Hampton (1999).
All biological parameters, selection patterns and yield time series are presented in Table 8 . 